\title{
A Resident-Created Hospitalist Curriculum for Internal Medicine Housestaff
}

\author{
Andre Kumar, MD*, Andrea Smeraglio, MD, Ronald Witteles, MD, Stephanie Harman, MD, Shriram Nallamshetty, MD, \\ Angela Rogers, MD, Robert Harrington, MD, Neera Ahuja, MD
}

Department of Medicine, Stanford University School of Medicine, Stanford, California.

The growth of hospital medicine has led to new challenges, and recent graduates may feel unprepared to meet the expanding clinical duties expected of hospitalists. At our institution, we created a resident-inspired hospitalist curriculum to address the training needs for the next generation of hospitalists. Our program provided 3 tiers of training: (1) clinical excellence through improved training in underemphasized areas of hospital medicine, (2) academic development through required research, quality improvement, and medical student teaching, and (3) career mentorship. In this article, we describe the genesis of our program, our final product, and the challenges of creating a curriculum while being internal medicine residents. Journal of Hospital Medicine 2016;11:646-649. (c) 2016 Society of Hospital Medicine
Hospital medicine has grown tremendously since its inception in the 1990s. ${ }^{1,2}$ This expansion has led to the firm establishment of hospitalists in medical education, quality improvement (QI), research, subspecialty comanagement, and administration. ${ }^{3-5}$

This growth has also created new challenges. The training needs for the next generation of hospitalists are changing given the expanded clinical duties expected of hospitalists. ${ }^{6-8}$ Prior surveys have suggested that some graduates employed as hospitalists have reported feeling underprepared in the areas of surgical comanagement, neurology, geriatrics, palliative care, and navigating the interdisciplinary care system. ${ }^{9,10}$

In keeping with national trends, the number of residents interested in hospital medicine at our institution has dramatically increased. As internal medicine residents interested in careers in hospitalist medicine, we felt that improving hospitalist training at our institution was imperative given the increasing scope of practice and job competitiveness. ${ }^{11,12}$ We therefore sought to design and implement a hospitalist curriculum within our residency. In this article, we describe the genesis of our program, our final product, and the challenges of creating a curriculum while being internal medicine residents.

*Address for correspondence and reprint requests: Andre Kumar, MD, Department of Medicine, Stanford University Hospital, 300 Pasteur Drive, Lane 154, Stanford, CA 94305-5133; Telephone: 650-723-6661; Fax: 650-498-6205; E-mail: akumar3@stanford.edu

Additional Supporting Information may be found in the online version of this article.

Received: September 8, 2015; Revised: March 6, 2016; Accepted: March 12, 2016

2016 Society of Hospital Medicine DOI 10.1002/jhm.2590

Published online in Wiley Online Library (Wileyonlinelibrary.com).

\section{METHODS}

\section{Needs Assessment}

To improve hospitalist training at our institution, we first performed a needs assessment. We contacted recent hospitalist graduates and current faculty to identify aspects of their clinical duties that may have been underemphasized during their training. Next, we performed a literature search in PubMed using the combined terms of "hospitalist," "hospital medicine," "residency," "education," "training gaps," or "curriculum." Based on these efforts, we developed a resident survey that assessed their attitudes toward various components of a potential curriculum. The survey was sent to all categorical internal medicine residents at our institution in December 2014. The survey specified that the respondents only include those who were interested in careers in hospital medicine. Responses were measured using a 5-point Likert scale $(1=$ least important to $5=$ most important $)$.

\section{Curriculum Development}

Our intention was to develop a well-rounded program that utilized mentorship, research, and clinical experience to augment our learner's knowledge and skills for a successful, long-term career in the increasingly competitive field of hospital medicine. When designing our curriculum, we accounted for our program's current rotational requirements and local culture. Several previously identified "underemphasized" areas within hospital medicine, such as palliative care and neurology, were already required rotations at our program. ${ }^{3-5}$ Therefore, any proposed curricular changes would need to mold into program requirements while still providing a preparatory experience in hospital medicine beyond what our current rotations offered. We felt this could be accomplished by including rotations that could provide specific skills pertinent to 
TABLE 1. Key Differences in Curriculum Requirements Between Our Internal Medicine Residency Program and the Hospitalist Curriculum

\begin{tabular}{lcc}
\hline Rotation & Non-SHAPE & SHAPE \\
\hline ICU & At least 12 weeks & At least 16 weeks \\
Medical wards & At least 16 weeks & At least 16 weeks \\
Ultrasound diagnostics & Elective & Required \\
Quality improvement & Elective & Required \\
Surgical comanagement & Elective & Required \\
Medicine consult & Elective & Required \\
Neurology & Required & Required \\
Palliative care & Required & Required \\
\hline
\end{tabular}

NOTE: Abbreviations: ICU, intensive care unit; SHAPE, Stanford Hospitalist Advanced Practice and Education.

hospital medicine, such as ultrasound diagnostics or QI.

\section{Meeting With Stakeholders}

We presented our curriculum proposal to the chief of the Stanford Hospital Medicine Program. We identified her early in the process to be our primary mentor, and she proved instrumental in being an advocate. After several meetings with the hospitalist group to further develop our program, we presented it to the residency program leadership who helped us to finalize our program.

\section{RESULTS}

\section{Needs Assessment}

Twenty-two out of 111 categorical residents in our program $(19.8 \%)$ identified themselves as interested in hospital medicine and responded to the survey. There were several areas of a potential hospitalist curriculum that the residents identified as important (defined as 4 or 5 on a 5 -point Likert scale). These areas included mentorship (90.9\% of residents; mean 4.6, standard deviation [SD] 0.7), opportunities to teach $(86.3 \%$; mean 4.4, SD 0.9), and the establishment of a formal hospitalist curriculum $(85.7 \%$; mean 4.2 , SD 0.8$)$. The residents also identified several rotations that would be beneficial (defined as a 4 or 5 on a 5 -point Likert scale). These included medicine consult/procedures team (95.5\% of residents; mean 4.7, SD 0.6), point-of-care ultrasound diagnostics $(90.8 \%$; mean 4.7, SD 0.8), and a community hospitalist preceptorship $(86.4 \%$; mean 4.4 , SD 1.0$)$. The residents also identified several rotations deemed to be of lesser benefit. These rotations included inpatient neurology (only $27.3 \%$ of residents; mean 3.2 , SD 0.8 ) and palliative care $(50.0 \%$; mean 3.5 , SD 1.0$)$.

\section{The Final Product: A Hospitalist Training Curriculum}

Based on the needs assessment and meetings with program leadership, we designed a hospitalist program and named it the Stanford Hospitalist Advanced Practice and Education (SHAPE) program. The program
BOX 1. The Stanford Hospitalist Advanced Practice and Education (SHAPE) program curriculum. Members of the program are required to complete the requirements listed before the end of their third year. Note that the clinical rotations are spread over the 3 years of residency.

Stanford Hospitalist Advanced Practice and Education Required Clinical Rotations

- Medicine Consult (2-4 weeks)

- Critical Care (16 weeks)

- Ultrasound Diagnostics (2 weeks)

- Quality Improvement (4 weeks)

- Inpatient Neurology (2 weeks)

- Palliative Care (2 weeks)

- Surgical Comanagement (2 weeks)

\section{Required Nonclinical Work}

- Quality improvement, clinical or educational project with a presentation at an academic conference or manuscript submission in a peer-reviewed journal

- Enrollment in the Stanford Faculty Development Center workshop on effective clinical teaching

- Attendance at the hospitalist lecture series (10 lectures): patient safety, hospital efficiency, fundamentals of perioperative medicine, healthcare structure and changing reimbursement patterns, patient handoff, career development, prevention of burnout, inpatient nutrition, hospitalist research, and lean modeling in the hospital setting

\section{Mentorship}

- Each participant is matched with 3 hospitalist mentors in order to provide comprehensive career and personal mentorship

was based on 3 core principles: (1) clinical excellence: by training in hospitalist-relevant clinical areas, (2) academic development: with required research, QI, and teaching, and (3) career mentorship.

\section{Clinical Excellence By Training in Hospitalist-Relevant Clinical Areas}

The SHAPE curriculum builds off of our institution's current curriculum with additional required rotations to improve the resident's skillsets. These included ultrasound diagnostics, surgical comanagement, and QI (Box 1). Given that some hospitalists work in an open intensive care unit (ICU), we increased the amount of required ICU time to provide expanded procedural and critical care experiences. The residents also receive 10 seminars focused on hospital medicine, including patient safety, QI, and career development (Box 1). 
Academic Development With Required Research and Teaching

SHAPE program residents are required to develop a QI, education, or clinical research project before graduation. They are required to present their work at a hospitalist conference or submit to a peer-reviewed journal. They are also encouraged to attend the Society of Hospital Medicine annual meeting for their own career development.

SHAPE program residents also have increased opportunities to improve their teaching skills. The residents are enrolled in a clinical teaching workshop. Furthermore, the residents are responsible for leading regular lectures regarding common inpatient conditions for first- and second-year medical students enrolled in a transitions-of-care elective.

\section{Career Mentorship}

Each resident is paired with 3 faculty hospitalists who have different areas of expertise (ie, clinical teaching, surgical comanagement, QI). They individually meet on a quarterly basis to discuss their career development and research projects. The SHAPE program will also host an annual resume-development and career workshop.

\section{SHAPE Resident Characteristics}

In its first year, 13 of 25 residents (52\%) interested in hospital medicine enrolled in the program. The SHAPE residents were predominantly second-year residents (11 residents, $84.6 \%$ ).

Among the 12 residents who did not enroll, there were 7 seniors $(58.3 \%)$ who would soon be graduating and would not be eligible.

\section{DISCUSSION}

The training needs of aspiring hospitalists are changing as the scope of hospital medicine has expanded. ${ }^{6}$ Residency programs can facilitate this by implementing a hospitalist curriculum that augments training and provides focused mentorship. ${ }^{13,14}$ An emphasis on resident leadership within these programs ensures positive housestaff buy-in and satisfaction.

There were several key lessons we learned while designing our curriculum because of our unique role as residents and curriculum founders. This included the early engagement of departmental leadership as mentors. They assisted us in integrating our program within the existing internal medicine residency and the selection of electives. It was also imperative to secure adequate buy-in from the academic hospitalists at our institution, as they would be our primary source of faculty mentors and lecturers.

A second challenge was balancing curriculum requirements and ensuring adequate buy-in from our residents. The residents had fewer electives over their second and third years. However, this was balanced by the fact that the residents were given first prefer- ence on historically desirable rotations at our institution (including ultrasound, medicine consult, and QI). Furthermore, we purposefully included current resident opinions when performing our needs assessment to ensure adequate buy-in. Surprisingly, the residents found several key rotations to be of low importance in our needs assessment, such as palliative care and inpatient neurology. Although this may seem confounding, several of these rotations (ie, neurology and palliative care) are already required of all residents at our program. It may be that some residents feel comfortable in these areas based on their previous experiences. Alternatively, this result may represent a lack of knowledge on the residents' part of what skill sets are imperative for career hospitalists. ${ }^{4,6}$

Finally, we recognize that our program was based on our local needs assessment. Other residency programs may already have similar curricula built into their rotation schedule. In those instances, a hospitalist curriculum that emphasizes scholarly advancement and mentorship may be more appropriate.

\section{CONCLUSIONS AND FUTURE DIRECTIONS}

At out institution, we have created a hospitalist program designed to train the next generation of hospitalists with improved clinical, research, and teaching skills. Our cohort of residents will be observed over the next year, and we will administer a follow-up study to assess the effectiveness of the program.

\section{Acknowledgements}

The authors acknowledge Karina Delgado, program manager at Stanford's internal medicine residency, for providing data on recent graduate plans.

Disclosures: Andre Kumar, MD, and Andrea Smeraglio, MD, are cofirst authors. The authors report no conflicts of interest.

\section{References}

1. Wachter RM. The hospitalist field turns 15: new opportunities and challenges. J Hosp Med. 2011;6(4):10-13.

2. Glasheen JJ, Epstein KR, Siegal E, Kutner JS, Prochazka AV. The spectrum of community based hospitalist practice: A call to tailor internal medicine residency training. Arch Intern Med. 2007;167:727729.

3. Pham HH, Devers KJ, Kuo S, Berenson R. Health care market trends and the evolution of hospitalist use and roles. J Gen Intern Med. 2005;20(2):101-107.

4. Lindenauer PK, Pantilat SZ, Katz PP, Wachter RM. Survey of the National Association of Inpatient Physicians. Ann Intern Med. 1999: 343-349.

5. Goldenberg J, Glasheen JJ. Hospitalist educators: future of inpatient internal medicine training. Mt Sinai J Med. 2008;75(5):430-435.

6. Glasheen JJ, Siegal EM, Epstein K, Kutner J, Prochazka AV. Fulfilling the promise of hospital medicine: tailoring internal medicine training to address hospitalists' needs. J Gen Intern Med. 2008;23(7):11101115.

7. Arora V, Guardiano S, Donaldson D, Storch I, Hemstreet P. Closing the gap between internal medicine training and practice: recommendations from recent graduates. Am J Med. 2005;118(6):680-685

8. Chaudhry SI, Lien C, Ehrlich J, et al. Curricular content of internal medicine residency programs: a nationwide report. Am J Med. 2014; 127(12):1247-1254.

9. Plauth WH, Pantilat SZ, Wachter RM, Fenton CL. Hospitalists' perceptions of their residency training needs: results of a national survey. Am J Med. 2001;111(3):247-254.

10. Holmboe ES, Bowen JL, Green M, et al. Reforming internal medicine residency training: a report from the Society of General Internal 
Medicine's Task Force for Residency Reform. J Gen Intern Med. 2005;20(12):1165-1172.

11. Goodman PH, Januska A. Clinical hospital medicine fellowships: perspectives of employers, hospitalists, and medicine residents. J Hosp Med. 2008;3(1):28-34.

12. Flanders SA, Centor B, Weber V, McGinn T, DeSalvo K, Auerbach A. Challenges and opportunities in academic hospital medicine: report from the Academic hospital medicine Summit. J Hosp Med. 2009; $4(4): 240-246$.

13. Glasheen JJ, Goldenberg J, Nelson JR. Achieving hospital medicine's promise through internal medicine residency redesign. Mt Sinai J Med. 2008;75(5):436-441.

14. Hauer, Karen E, Flanders, Scott A, Wachter RM. Training Future Hospitalists. Cult Med. 1999;171(12):367-370. 